\title{
A Comparative Study on Alexithymia in Depressive, Somatoform, Anxiety, and Psychotic Disorders among Koreans
}

\author{
Sung hwa Son 1 , Hyunyoung Jo², Hyo Deog Rim¹, Ju Hee Kim³, \\ Hea Won $\mathrm{Kim}^{4}$, Geum Ye Bae ${ }^{1}$ and Seung Jae Lee ${ }^{1 凶}$ \\ 'Department of Psychiatry, School of Medicine, Kyungpook National University, Daegu, Republic of Korea \\ 2Department of Psychiatry, Daedong Hospital, Daegu, Republic of Korea \\ ${ }^{3}$ Department of Psychiatry, Pohang St. Mary's Hospital, Pohang, Republic of Korea \\ ${ }^{4}$ Department of Psychiatry, Daegu Mental Hospital, Daegu, Republic of Korea
}

Objective Little is known about the characteristic differences in alexithymic construct in various psychiatric disorders because of a paucity of direct comparisons between psychiatric disorders. Therefore, this study explored disorder-related differences in alexithymic characteristics among Korean patients diagnosed with four major psychiatric disorders $(\mathrm{n}=388)$.

Methods Alexithymic tendencies, as measured by the Korean version of the 20-item Toronto Alexithymia Scale (TAS-20K), of patients classified into four groups according to major psychiatric diagnosis were compared. The groups consisted of patients with depressive disorders (DP; $n=125$ ), somatoform disorders (SM; $n=78$ ), anxiety disorders (AX; $n=117$ ), and psychotic disorders (PS; $n=68$ ).

Results We found that substantial portions of patients in all groups were classified as having alexithymia and no statistical intergroup differences emerged $(42.4 \%, 35.9 \%, 35.3 \%$, and 33.3\% for DP, SM, PS, and AX). However, patients with DP obtained higher scores in factor 2 (difficulties describing feelings) than those with SM or AX, after adjusting for demographic variables.

Conclusion These findings suggest that alexithymia might be associated with a higher vulnerability to depressive disorders and factor 2 of TAS-20K could be a discriminating feature of depressive disorders.

Psychiatry Investig 2012;9:325-331

Key Words Alexithymia, Depressive disorder, Somatoform disorder, Anxiety disorder, Psychotic disorder.

\section{INTRODUCTION}

In the early 1970s, Sifneos et al. introduced the term "alexithymia," derived from the Greek words a (lack), lexis (word), and thymos (emotion). ${ }^{1,2}$ Alexithymia was originally defined as the inability to recognize and verbalize emotions, and has since been characterized as an emptiness of feelings, an impoverished imagination or fantasy life, difficulties in interpersonal communication, and a lack of positive emotions and a high prevalence of negative emotions. ${ }^{3,4}$ Subsequently, Taylor et al. ${ }^{5}$ proposed that alexithymia reflected a deficit in the cognitive processing of emotions or, more generally, a

Received: February 12, 2012 Revised: June 9, 2012

Accepted: June 26, 2012 Available online: November 14, 2012

$\triangle$ Correspondence: Seung Jae Lee, MD, PhD

Department of Psychiatry, School of Medicine, Kyungpook National University, 200 Dongdeok-ro, Jung-gu, Daegu 700-721, Republic of Korea Tel: +82-53-420-5747, Fax: +82-53-426-5361, E-mail: jayleemd@knu.ac.kr

(c) This is an Open Access article distributed under the terms of the Creative Commons Attribution Non-Commercial License (http://creativecommons.org/licenses/bync/3.0) which permits unrestricted non-commercial use, distribution, and reproduction in any medium, provided the original work is properly cited. disturbance in the regulation of emotions.

Alexithymic features were first assumed to be typical of patients with classical psychosomatic diseases. However, further studies have shown that an alexithymic communicative style is not specific to patients with classical psychosomatic diseases. ${ }^{6}$ A growing number of studies have indicated that alexithymia exists in various psychiatric disorders such as depressive disorders, ${ }^{7-12}$ somatoform disorders, ${ }^{13-17}$ anxiety disorders, ${ }^{18-22}$ and schizophrenia. ${ }^{23-26}$ More specifically, alexithymia has been associated with certain psychiatric features such as somatization, ${ }^{27-30}$ depression, ${ }^{31}$ and dissociation. ${ }^{32,33}$ The prevalence of alexithymia was from $10 \%$ up to $18 \%$ even among general population. ${ }^{34-39}$

However, most previous studies have shown only that substantial portions of patients with a given psychiatric illness demonstrated alexithymia, and that this prevalence rate was higher than that in normal subjects. Surprisingly, owing to the paucity of direct comparisons between psychiatric disorders, little is known about the characteristic differences in alexithymic construct among various psychiatric disorders. 
Bankier et al..$^{40}$ conducted a direct comparative evaluation of alexithymia in patients with somatoform, panic, obsessivecompulsive, and depressive disorder, taking into account the multidimensionality of the alexithymia. Duddu and colleagues, comparing between somatoform and depressive disorders, reported that while total alexithymia scores did not differentiate somatoform from depressive disorders, the two diagnostic groups did differ insofar as subjects with depression demonstrated greater difficulty in expressing feelings. ${ }^{16}$ SubicWrana et al. ${ }^{41}$ also revealed that significant diagnosis-related differences were not observed among the mean scores of the six diagnostic groups (i.e., depression, anxiety and compulsiveobsessive disorders, adjustment disorder, somatoform disorders, psychological factors with somatic disorders, and eating disorders) on the Toronto Alexithymia Scale-20 (TAS-20). ${ }^{42}$ Despite the value of the findings emanating from these studies, their limited sample sizes and differences in the sample selection criteria limit the generalizability of the results. Although our group reported the relationship between severity of symptoms of depression and alexithymia in patients with depressive disorders in Korea, no study has been conducted for the relationship between alexithymia and different diagnostic groups among Korean subjects. ${ }^{43}$

Thus, the aim of the present study was to compare the prevalence of alexithymia in four major mental disorders and to investigate whether there were differences in construct of alexithymia among them. We compared alexithymic tendencies, as measured by the TAS-20K, of four diagnostic groups (i.e., depressive, somatoform, anxiety and psychotic disorders) among a large sample size to explore the disorder-related differences in alexithymic construct. These four disorders were chosen for this comparison because depressive and somatoform disorders are the two diagnoses that most commonly co-occur with alexithymic tendencies and differences between the alexithymic characteristics in depressive and anxiety disorders are of great interest due to the high levels of comorbidity between these two conditions. Moreover, patients with psychotic disorders, primarily schizophrenia, were included to enable comparisons between neurotic and psychotic disorders. We also considered sociodemographic and clinical variables including severity and duration of illness.

\section{METHODS}

\section{Subjects and procedures}

The sample was drawn from patients at Kyungpook National University Hospital, Daegu, Korea, between January 2003 and March 2007. Assessments included administration of the Korean version of the 20-item Toronto Alexithymia Scale (TAS-20K) as well as chart reviews. Those with depres- sive, somatoform, anxiety, and psychotic disorders, as per DSM-IV criteria, were included. Exclusion criteria included age under 18 years, patients with any comorbid axis I psychiatric disorders, mental retardation, and any neurologic condition that might influence the ability to self-report. Adjustment disorder as well as mixed anxiety and depressive disorder, currently categorized within anxiety disorder NOS were also excluded because of their vague and mixed characteristics.

Demographic and psychosocial characteristics (i.e., sex, age, and level of education), and psychological assessment data (TAS-20K) were evaluated at the time of patient's first visit. Clinical information (i.e., primary and comorbid DSMIV psychiatric diagnoses at the time of psychological evaluation, duration of illness, and Clinical Global Impression scores) were assessed through chart reviews.

Two experienced psychiatrists (J.H.K. and H.W.K.) reviewed the charts of 868 patients, confirmed previous diagnoses, and determined CGI scores based on patient records. After training for the CGI rating, the CGI of 30 randomly selected charts were rated independently by 2 raters and its inter-rater reliability was high (Spearman rho $=0.87$ ). Data on 388 inpatients and outpatients in psychiatric treatment during this 4-year period were collected and analyzed. This study was approved by the institutional review board of Kyungpook National University Hospital.

\section{Psychological scales}

\section{The 20-item Toronto Alexithymia Scale (TAS-20)}

The TAS-20 has become the most widely used measure of the alexithymia construct. ${ }^{42}$ This self-report questionnaire measures three intercorrelated dimensions of the alexithymia construct: 1) difficulties identifying feelings, 2) difficulties describing feelings, and 3) externally oriented thinking. Each TAS-20 item was rated on a 5-point Likert scale, with total scores ranging from 20 to 100 . The cutoff point used for alexithymia was $\geq 61 .{ }^{44}$ The study by Lee et al. ${ }^{45}$ reported how the TAS-20 was translated into Korean (TAS-20K). Using confirmatory factor analysis, these authors showed that the threefactor structure of the original scale was consistent with the Korean version of the scale (Cronbach's $\alpha=0.76$ ).

\section{Clinical Global Impression-Severity Scale}

The CGI-Severity (CGI-S) was used to assess the clinician's impression of the current state of the patient's illness. ${ }^{46}$ The rater was asked to "consider his/her total clinical experience with the given population." The time span considered is the week prior to the rating; and the following scores can be given: $1=$ normal, not at all ill, $2=$ borderline mentally ill, $3=\mathrm{mi}-$ ldly ill, 4=moderately ill, 5=markedly ill, $6=$ severely ill, and 
7=among the most extremely ill patients.

\section{Statistical analysis}

Categorical cross-tabulations were examined for gender and alexithymia/non-alexithymia using the $\chi^{2}$ statistics. Between-group differences were compared in terms of demographic (e.g., age, education), clinical (e.g., duration of illness) and psychological variables (e.g., CGI score) using one-way analysis of variance (ANOVA) with post hoc Tukey's tests. Since the TAS-20K total and subfactor scores violated the assumption of normality, the Kruskal-Wallis test was used to compare these scores between diagnostic groups. Then, we followed up the main analysis with Mann-Whitney tests between pairs of groups, but only accepted them as significant if they were significant below $0.008(0.05 /$ number of tests $=$ 0.05/6).

Using a hierarchical regression analyses, age, gender, education, CGI score, and the duration of illness were entered in step one. The three dummy coding variables, with depressive group as baseline, were added in step two to examine the influence of particular DSM-IV disorders (i.e., psychotic, depressive, anxiety, and somatoform disorders) on alexithymia, as measured by total and subfactors scores on the TAS-20K. To avoid confusing interpretations of the comparative results between groups, depressive group, which is known to be the most alexithymic based on previous literature, was used as baseline.
The $\alpha$ level of significance was set at .05 for all the statistical analyses. All the statistical analyses were performed with SPSS for Windows software (version 12.0; SPSS Inc., Chicago, IL). Values are means \pm standard deviation (SD), unless otherwise noted.

\section{RESULTS}

\section{Demographic and clinical characteristics}

The average age of the study sample $(n=388)$ was 40.2 years $( \pm 15.7)$ and $46 \%$ of the sample $(n=178)$ were women. The sample consisted of 125 patients were categorized as DSMIV depressive disorder (DP); 78 as somatoform disorder (SM); 117 as anxiety disorder (AX); 68 as psychotic disorder (PS). The mean CGI-S score was $3.38 \pm 0.95$, indicating mildly to moderately ill.

We found significant group differences with regard to gender, age, and education. Post hoc analyses revealed that subjects with PS were the youngest and those with SM were the oldest. The SM group was the least educated. As expected, the clinical severity of patients with PS was significantly higher than that of the other groups, and the clinical severity of patients with SM was lower than that of other groups. However, no significant group differences emerged in relation to the duration of illness. Table 1 shows the demographic and clinical data for each psychiatric disorder group, including main Axis I diagnoses in detail.

Table 1. Demographic and clinical information $(\mathrm{N}=388)$

\begin{tabular}{|c|c|c|c|c|c|c|c|}
\hline & \multirow{2}{*}{$\begin{array}{l}\text { Depressive disorder } \\
\qquad(\mathrm{N}=125)\end{array}$} & \multirow{2}{*}{$\begin{array}{l}\text { Somatoform disorder } \\
\qquad(\mathrm{N}=78)\end{array}$} & \multirow{2}{*}{$\begin{array}{l}\text { Anxiety disorder } \\
(\mathrm{N}=117)\end{array}$} & \multirow{2}{*}{$\begin{array}{l}\text { Psychotic disorder } \\
\qquad(\mathrm{N}=68)\end{array}$} & \multicolumn{3}{|c|}{ Statistics } \\
\hline & & & & & $\chi^{2}$ or $F$ & $\mathrm{df}$ & $\mathrm{p}$ \\
\hline \multicolumn{8}{|l|}{ Demographic characteristics } \\
\hline Gender, male/female & $68 / 57$ & $29 / 49$ & $75 / 42$ & $38 / 30$ & 8.5 & 3 & 0.037 \\
\hline Age $^{*}$, year & $41.4(16.5)$ & $49.5(13.4)$ & $39.3(14.4)$ & $29.1(10.5)$ & 23 & 3,384 & $<0.001$ \\
\hline Education ${ }^{\dagger}$, year & $11.7(4.1)$ & $10.5(4.4)$ & $12.0(3.7)$ & $12.6(2.9)$ & 4.0 & 3,378 & 0.008 \\
\hline \multicolumn{8}{|l|}{ Clinical characteristics } \\
\hline CGI-severity $\ddagger$ & $3.4(0.9)$ & $2.9(0.7)$ & $3.4(0.9)$ & $4.1(1.1)$ & 23.4 & 3,381 & $<0.001$ \\
\hline Duration of illness, year & $3.4(4.4)$ & $4.2(7.0)$ & $3.2(5.5)$ & $3.8(5.6)$ & 0.63 & 3,380 & 0.605 \\
\hline $\begin{array}{l}\text { Main DSM-IV Axis } \\
\text { I diagnosis (number) }\end{array}$ & $\begin{array}{l}\text { Major depressive } \\
\text { disorder (41), } \\
\text { dysthymic disorder } \\
\text { (52), depressive } \\
\text { disorder NOS (32) }\end{array}$ & $\begin{array}{l}\text { Somatization disorder (5), } \\
\text { undifferentiated somato } \\
\text { form disorder (6), } \\
\text { conversion disorder (3), } \\
\text { hypochondriasis (2), } \\
\text { pain disorder (1), } \\
\text { somatoform disorder } \\
\text { NOS (61) }\end{array}$ & $\begin{array}{l}\text { Panic disorder (21), } \\
\text { OCD (16), PTSD } \\
(26), \text { ASD (11), } \\
\text { GAD (17), social } \\
\text { phobia (4), anxiety } \\
\text { disorder NOS } \\
\text { except MADD (22) }\end{array}$ & $\begin{array}{l}\text { Schizophrenia (45), } \\
\text { schizophreniform } \\
\text { disorder (5), } \\
\text { schizoaffective } \\
\text { disorder (1), } \\
\text { psychotic disorder } \\
\text { NOS (17) }\end{array}$ & & & \\
\hline
\end{tabular}

Values are means (SD). * psychotic disorder vs. the other groups, somatoform disorder vs. the other groups, with all p's $<0.001,{ }^{\dagger}$ somatoform disorder vs. psychotic disorder $(\mathrm{p}=0.006)$ and anxiety disoder $(\mathrm{p}=0.041)$, ${ }^{\ddagger} \mathrm{psychotic}$ disorder vs. the other groups $($ all $\mathrm{p}$ ' $<0.001)$, somatoform disorder vs. depressive disorder ( $\mathrm{p}=0.003$ ). NOS: not otherwise specified, CGI: clinical global impression, OCD: obsessive-compulsive disorder, ASD: acute stress disorder, PTSD: posttraumatic stress disorder, GAD: generalized anxiety disorder, MADD: mixed anxiety-depressive disorder 


\section{Alexithymia and TAS-20K score}

Subjects with DP (58.6 \pm 11.0$)$ exhibited the highest mean TAS-20K total scores, followed by those with $\mathrm{AX}(57.8 \pm 10.8)$, SM (55.7 \pm 10.7$)$, and PS (55.6 \pm 13.6$) .42 .4 \%$ of patients with DP had alexithymia; the corresponding figures, in descending order, were $35.9 \%$ for SM, 35.3\% for PS, and 33.3\% for AX. However, no statistically significant group differences were observed not only in the TAS-20K total score $\left(\mathrm{H}_{3}=4.6, \mathrm{p}=0.202\right)$ but in the prevalence of alexithymia $\left(X^{2}=2.4, \mathrm{df}=3, \mathrm{p}=0.501\right)$ (Table 2).

For the TAS-20K subfactors, only factor 2 was significant between-group difference $\left(\mathrm{H}_{3}=8.3, \mathrm{p}=0.040\right)$ and post hoc comparisons indicated that patients with DP exhibited higher scores on factor 2 than those with SM ( $U=3784.5, \mathrm{p}=0.007)$ (Table 2).

\section{Relationships of TAS-20K total scores and subfactors with different DSM-IV disorder}

Step 1 in hierarchical regression analyses revealed that age was negatively correlated with the TAS-20 K total score, and factor $1,2(\mathrm{p}<0.01)$ but not with factor 3 . Education was negatively associated with total score and factor $1(\mathrm{p}<0.05)$. These patterns were similar in the step 2 analyses (Table 3 ).

Step 2, in which we entered three new dummy variables for

Table 2. Differences on TAS-20K scores among diagnostic groups

\begin{tabular}{|c|c|c|c|c|c|c|c|}
\hline & \multicolumn{2}{|c|}{ Depressive disorder Somatoform disorder } & \multirow{2}{*}{$\begin{array}{l}\text { Anxiety disorder } \\
\qquad(\mathrm{N}=117)\end{array}$} & \multirow{2}{*}{$\begin{array}{l}\text { Psychotic disorder } \\
\qquad(\mathrm{N}=68)\end{array}$} & \multicolumn{3}{|c|}{ Statistics } \\
\hline & $(\mathrm{N}=125)$ & $(\mathrm{N}=78)$ & & & $\chi^{2}$ or $\mathrm{H}^{\dagger}$ & $\mathrm{df}$ & $\mathrm{p}$ \\
\hline Alexithymia \% (number) & $42.4(53)$ & $35.9(28)$ & $33.3(39)$ & $35.3(24)$ & 5.2 & 3 & 0.157 \\
\hline TAS-20K total & $58.6(11.0)$ & $55.7(10.7)$ & $57.8(10.8)$ & $55.6(13.6)$ & 4.6 & 3 & 0.202 \\
\hline TAS-20K factor 1 & $20.9(6.1)$ & $19.9(6.5)$ & $20.4(6.5)$ & $18.7(7.5)$ & 4.9 & 3 & 0.179 \\
\hline TAS-20K factor $2^{*}$ & $16.0(4.2)$ & $14.4(4.2)$ & $15.1(4.1)$ & $14.9(5.2)$ & 8.3 & 3 & 0.040 \\
\hline TAS-20K factor 3 & $21.7(4.4)$ & $21.4(3.9)$ & $22.3(3.8)$ & $22.0(4.1)$ & 2.3 & 3 & 0.521 \\
\hline
\end{tabular}

Values are mean (SD) except Alexithymia \%. *depressive disorder vs. somatoform disorder with $\mathrm{p}=0.007$ by post hoc Mann-Whitney test, ${ }^{\dagger} \mathrm{H}$ denotes the test statistic for the Kruskal-Wallis test. factor 1: difficulties identifying feelings, factor 2: difficulties describing feelings, factor 3: externally oriented thinking. TAS-20K: Korean version of the 20-item Toronto Alexithymia Scale

Table 3. Relationships of TAS-20K total scores and subfactors with multiple variables (hierarchical multiple regression analyses)

\begin{tabular}{|c|c|c|c|c|c|c|c|c|c|c|c|c|}
\hline & \multicolumn{3}{|c|}{ TAS-20K total ${ }^{\dagger}$} & \multicolumn{3}{|c|}{ Factor $1^{\ddagger}$} & \multicolumn{3}{|c|}{ Factor $2^{\S}$} & \multicolumn{3}{|c|}{ 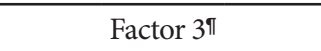 } \\
\hline & $\mathrm{B}$ & SE B & $\beta$ & B & SE B & $\beta$ & B & SE B & $\beta$ & B & SE B & $\beta$ \\
\hline \multicolumn{13}{|l|}{ Step 1} \\
\hline Constant & 67.09 & 4.38 & & 25.68 & 2.54 & & 17.03 & 1.67 & & 24.37 & 1.56 & \\
\hline Age & -0.15 & 0.04 & $-0.20^{* *}$ & -0.07 & 0.03 & $-0.17^{* *}$ & -0.05 & 0.02 & $-0.17^{* *}$ & -0.03 & 0.02 & -0.11 \\
\hline Gender & 1.72 & 1.20 & 0.07 & 0.81 & 0.70 & 0.06 & 0.54 & 0.46 & 0.06 & 0.37 & 0.43 & 0.04 \\
\hline Education & -0.35 & 0.17 & $-0.12^{*}$ & -0.24 & 0.10 & $-0.14^{*}$ & 0.00 & 0.06 & 0.00 & -0.11 & 0.06 & -0.11 \\
\hline CGI & -0.24 & 0.64 & -0.02 & -0.12 & 0.37 & -0.02 & -0.07 & 0.24 & -0.01 & -0.05 & 0.23 & -0.01 \\
\hline DOI & -0.03 & 0.11 & -0.01 & 0.00 & 0.06 & 0.00 & -0.02 & 0.04 & -0.02 & -0.01 & 0.04 & -0.02 \\
\hline \multicolumn{13}{|l|}{ Step 2} \\
\hline Constant & 68.27 & 4.48 & & 26.08 & 2.59 & & 18.03 & 1.71 & & 24.16 & 1.61 & \\
\hline Age & -0.18 & 0.05 & $-0.24^{* *}$ & -0.09 & 0.03 & $-0.22^{* *}$ & -0.06 & 0.02 & $-0.20^{* *}$ & -0.03 & 0.02 & -0.10 \\
\hline Gender & 1.71 & 1.21 & 0.07 & 0.88 & 0.70 & 0.07 & 0.56 & 0.46 & 0.06 & 0.28 & 0.44 & 0.03 \\
\hline Education & -0.35 & 0.17 & $-0.12^{*}$ & -0.24 & 0.10 & $-0.14^{*}$ & 0.00 & 0.06 & 0.00 & -0.11 & 0.06 & -0.11 \\
\hline CGI-S & 0.24 & 0.67 & 0.02 & 0.25 & 0.39 & 0.04 & 0.04 & 0.26 & 0.01 & -0.05 & 0.24 & -0.01 \\
\hline DOI & -0.01 & 0.11 & 0.00 & 0.01 & 0.06 & 0.01 & -0.01 & 0.04 & -0.01 & -0.01 & 0.04 & -0.02 \\
\hline SM vs. DP & -5.48 & 1.85 & $-0.18^{* *}$ & -3.51 & 1.07 & $-0.20^{* *}$ & -2.17 & 0.71 & $-0.19^{* *}$ & 0.20 & 0.67 & 0.02 \\
\hline AX vs. DP & -1.03 & 1.48 & -0.04 & -0.49 & 0.85 & -0.03 & -1.21 & 0.56 & $-0.13^{*}$ & 0.67 & 0.53 & 0.08 \\
\hline PS vs. DP & -1.51 & 1.71 & -0.05 & -0.22 & 0.99 & -0.01 & -1.13 & 0.65 & -0.10 & -0.15 & 0.62 & -0.02 \\
\hline
\end{tabular}

${ }^{*} \mathrm{p}<0.05,{ }^{* *} \mathrm{p}<0.01,{ }^{\dagger} \mathrm{R}^{2}=0.042$ for Step $1 ; \Delta \mathrm{R}^{2}=0.023$ for Step 2 ( $\left.\mathrm{p}=0.007, \mathrm{p}=0.002\right),{ }^{\ddagger} \mathrm{R}^{2}=0.031$ for Step $1 ; \Delta \mathrm{R}^{2}=0.029$ for Step 2 ( $\mathrm{p}=0.039$, $\mathrm{p}=0.003$ ), ${ }^{\S} \mathrm{R}^{2}=0.038$ for Step $1 ; \Delta \mathrm{R}^{2}=0.028$ for Step 2 ( $\left.\mathrm{p}=0.013, \mathrm{p}=0.001\right),{ }^{\pi} \mathrm{R}^{2}=0.017$ for Step $1 ; \Delta \mathrm{R}^{2}=0.006$ for Step 2 (not significant). CGI-S: clinical global impression-severity, DOI: duration of illness, SM: somatoform disorder, DP: depressive disorder, AX: anxiety disorder, PS: psychotic disorder, factor 1: difficulties identifying feelings, factor 2: difficulties describing feelings, factor 3: externally oriented thinking, TAS20K: Korean version of the 20-item Toronto Alexithymia Scale 
psychiatric disorders, showed that subjects with DP obtained higher TAS-20K total and factor 1 score compared to those with SM. Patients with DP obtained significantly higher scores to factor 2 than patients with SM or AX, but there was no significance between DP and PS. Factor 3 was not predicted by the presence of PS, AX, or SM (Table 3).

\section{DISCUSSION}

This study explored the disorder-related differences in alexithymic construct among four major psychiatric disorder groups. We found that substantial portions of patients in all groups met criteria for alexithymia and no statistical intergroup differences in percentage of alexithymia and TAS-20K total score emerged $(42.4 \%, 35.9 \%, 35.3 \%$, and $33.3 \%$ for DP, SM, PS, and AX, respectively). However, patients with DP obtained higher scores in factor 2 (difficulties describing feelings) than those with SM or AX, after adjusting for demographic variables.

In our study, patients with DP obtained the highest TAS$20 \mathrm{~K}$ total scores $(58.6 \pm 11.0)$ and exhibited the highest rates of alexithymia (42.4\%), although statistical significance disappeared after adjusting for other demographic variables. These findings have been largely corroborated by previous studies that directly compared those psychiatric disorders showing the highest TAS-20 total scores with depressive disorders, regardless of whether such differences were significant. ${ }^{16,40,41}$ And the prevalence of alexithymia varied, ranging from 32 to $46 \%{ }^{8,9,31,47}$ Recently, Leweke et al. ${ }^{48}$ demonstrated a significantly increased proportion of alexithymic patients in depressive disorders (26.9\%), as compared to other diagnostic groups and suggested that high levels of alexithymia in depressive patients may be an expression of the negative view of the self or may indicate emotional numbness.

Of interest is the fact that our regression analysis revealed that patients with DP scored significantly higher than those with SM or AX in factor 2. Duddu et al. ${ }^{16}$ reported that patients with depressive disorder demonstrated more difficulty than those with somatoform disorders in describing feelings. Bankier et al. and Leweke et al. also demonstrated that depression was significantly associated with scores on factor $2 .^{40,48}$

Indeed, Saarijärvi et al. ${ }^{47}$ conducted a 1 -year prospective study revealing that changes in alexithymia were associated with changes in the depression and these associations were explained by the changes in factor 1 and 2. They also reported that factor 1 (difficulties identifying feelings) decreased, whereas factor 2 did not change significantly during the follow-up, suggesting that the latter represents a relatively constant trait. Thus, our findings, consistent with those of previous studies, suggest that factor 2 might be able to discrimi- nate between depressive disorders and other psychiatric disorders. Although the reason why factor 2 might be easily affected in depressive patients was still unknown, we speculated that patient with DP may feel more difficulties describing their emotions subjectively than those in other groups since they typically engage emotional inhibition strategy to deal with their symptoms, manifested as guilty or ambivalent feeling.

Contrary to generally held ideas that somatizing subjects experience greater difficulty expressing their emotions, our result of relatively low TAS-20K score in SM was consistent with the observations made by Duddu et al. ${ }^{16}$ who compared somatoform disorder and depressive disorder groups, each of which consisted of 30 subjects. Subic-Wrana et al. also did not find higher levels of alexithymia for somatoform disorders compared to other diagnostic groups, using both the Levels of Emotional Awareness Scale and TAS-20. ${ }^{41}$ In this regard, Lumley et al. ${ }^{49}$ proposed that the relatively emotionless descriptions of autobiographical details by somatoform patients may rather show a tendency to focus on somatic factors by disregarding emotional biographic aspects than a deficit in affectprocessing.

Previous findings on anxiety disorders have differed across studies; rates of alexithymia varied from $12 \%$ to $60 \%$, according to the particular diagnosis within the genre of anxiety disorders. ${ }^{20-22}$ Within our sample of various anxiety disorders, $33.3 \%$ of patients were proven to be alexithymic. Overall, patients with AX did not differ from patients with other disorders in terms of TAS-20K total and subfactor scores, with the exception of the scores on factor 2 obtained by those diagnosed with DP.

This study found that the mean total TAS-20K score of patients with PS was $55.6 \pm 13.6$, and that $35.3 \%$ of this diagnostic group was classified as having alexithymia. These figures are congruent with those of previous studies, ${ }^{24,26,50}$ especially those reported by Maggini and Raballo showing a mean of $55.3 \pm 17.4$ among 76 outpatients with schizophrenia (Maggini). Regardless of whether alexithymia and symptoms in schizophrenia (anhedonia, blunt affect, and alogia) are independent constructs $^{24,44}$ or not, ${ }^{23,25}$ a substantial number of patients with PS had alexithymia, comparable to other disorder groups. Moreover, in the present study, subjects with PS were not significantly different from subjects with DP in TAS-20K total and subfactor scores even after adjusting for demographic and clinical variables. These findings suggest that alexithymia might be a sharing domain between depressive disorders and psychotic disorders. For example, Maggini et al. ${ }^{50}$ showed that impairment in receptive (disturbances in understanding the meaning of words) and expressive (disturbances in finding adequate words) language, which is a personality dimension related to alexithymia, was associated with a depressive dimension in 
schizophrenia. To address this issue, it would be valuable to compare depressive patients with and those without psychotic features in the future.

In contrast to initial findings that TAS-20 scores and sociodemographic variables (e.g., age, gender, educational level, and socioeconomic status) were not associated, ${ }^{36}$ several studies have indicated that male gender, older age, and low educational level were related to alexithymia. ${ }^{51,52}$ These observations, offered with respect to general populations, were applicable to our psychiatric sample. In our study, low educational level was positively related to total scores on the TAS$20 \mathrm{~K}$. However, age was negatively correlated with total scores on the TAS-20K. The negative correlation with age may be due primarily to the epidemiological characteristic of each diagnostic group. That is, the mean age of patients with SM having relatively lower means of the TAS-20K scores was significantly higher than the mean age of patients with DP who had the highest means of the TAS-20K scores. A comparable study among psychiatric patients with various diagnoses showed that TAS-20K total scores were related to low educational levels, but not to gender or age. ${ }^{40}$

There are some limitations of our study. First, owing to the retrospective study design, some data, such as those regarding diagnosis and disease severity, could be biased despite thorough reviews of all data and consequent discarding of improper data. Second, hierarchically, the highest categories of disorder in the DSM-IV classification were compared. Thus, disease-specific variables that might affect the presence of alexythymia were not well controlled. Third, since a control group consisting of healthy normal subjects was not included, this study did only present the relative comparative data between psychiatric disorders. In the same context, note that alexithymic tendency only explained a small amount of the variation in psychiatric disorders

Regardless of these limitations, this comparative study has some methodological strength; the sample size was relatively large, including most of the common psychiatric disorders, the comorbid conditions that can be interfere the clear comparison were strictly excluded, and relevant covariates (age, gender and education level) were taken into account.

In conclusion, this comparative study showed that substantial portions of Korean patients in all diagnostic groups had alexithymia. Among subfactors, factor 2 might identify patients with depressive disorders since the latter obtained higher scores relative to the other diagnostic groups, after adjusting for other demographic variables.

\section{Acknowledgments}

This research was supported by Kyungpook National University Research Fund, 2012. The poster of this paper was presented and won the poster award at fall $2008 \mathrm{KNPA}$ Annual Meeting.

\section{REFERENCES}

1. Sifneos PE, Apfel-Savitz R, Frankel FH. The phenomenon of 'alexithymia. Observations in neurotic and psychosomatic patients. Psychother Psychosom 1977;28:47-57.

2. Sifneos PE. The prevalence of 'alexithymic' characteristics in psychosomatic patients. Psychother Psychosom 1973;22:255-262.

3. Taylor GJ. The alexithymia construct: conceptualization, validation, and relationship with basic dimensions of personality. New Trends Exp Clin Psychiatry 1994;10:61-74.

4. Sifneos PE. Affect, emotional conflict, and deficit: an overview. Psychother Psychosom 1991;56:116-122.

5. Taylor GJ, Bagby RM, Parker JD. The alexithymia construct: a potential paradigm for psychosomatic medicine. Psychosomatics 1991;32: 153-164.

6. Taylor GJ. Psychosomatic Medicine and Contemporary Psychoanalysis. Madison: International Institute Press; 1987.

7. Honkalampi KI, Hintikka J, Koivumaa-Honkanen H, Antikainen R, Haatainen K, Viinamaki H. Long-term alexithymic features indicate poor recovery from depression and psychopathology. A six-year follow-up. Psychother Psychosom 2007;76:312-314.

8. Honkalampi K, Hintikka J, Laukkanen E, Lehtonen J, Viinamaki H. Alexithymia and depression: a prospective study of patients with major depressive disorder. Psychosomatics 2001;42:229-234.

9. Honkalampi K, Saarinen P, Hintikka J, Virtanen V, Viinamaki H. Factors associated with alexithymia in patients suffering from depression. Psychother Psychosom 1999;68:270-275.

10. Wise TN, Mann LS, Hill B. Alexithymia and depressed mood in the psychiatric patient. Psychother Psychosom 1990;54:26-31.

11. Wise TN, Jani NN, Kass E, Sonnenschein K, Mann LS. Alexithymia: relationship to severity of medical illness and depression. Psychother Psychosom 1988;50:68-71.

12. Parker JD, Bagby RM, Taylor GJ. Alexithymia and depression: distinct or overlapping constructs? Compr Psychiatry 1991;32:387-394.

13. Bach M, Bach D. Predictive value of alexithymia: a prospective study in somatizing patients. Psychother Psychosom 1995;64:43-48.

14. Bach M, Bach D. Alexithymia in somatoform disorder and somatic disease: a comparative study. Psychother Psychosom 1996;65:150-152.

15. Burba B, Oswald R, Grigaliunien V, Neverauskiene S, Jankuviene O, Chue P. A controlled study of alexithymia in adolescent patients with persistent somatoform pain disorder. Can J Psychiatry 2006;51:468-471.

16. Duddu V, Isaac MK, Chaturvedi SK. Alexithymia in somatoform and depressive disorders. J Psychosom Res 2003;54:435-438.

17. Cox BJ, Kuch K, Parker JD, Shulman ID, Evans RJ. Alexithymia in somatoform disorder patients with chronic pain. J Psychosom Res 1994;38: 523-527.

18. Heinrichs M, Wagner D, Schoch W, Soravia LM, Hellhammer DH, Ehlert U. Predicting posttraumatic stress symptoms from pretraumatic risk factors: a 2-year prospective follow-up study in firefighters. Am J Psychiatry 2005;162:2276-2286.

19. Spitzer C, Vogel M, Barnow S, Freyberger HJ, Grabe HJ. Psychopathology and alexithymia in severe mental illness: the impact of trauma and posttraumatic stress symptoms. Eur Arch Psychiatry Clin Neurosci 2007;257:191-196.

20. Zeitlin SB, McNally RJ. Alexithymia and anxiety sensitivity in panic disorder and obsessive-compulsive disorder. Am J Psychiatry 1993;150: 658-660.

21. Parker JD, Taylor GJ, Bagby RM, Acklin MW. Alexithymia in panic disorder and simple phobia: a comparative study. Am J Psychiatry 1993; 150:1105-1107.

22. Cox BJ, Swinson RP, Shulman ID, Bourdeau D. Alexithymia in panic disorder and social phobia. Compr Psychiatry 1995;36:195-198.

23. van't Wout M, Aleman A, Bermond B, Kahn RS. No words for feelings: alexithymia in schizophrenia patients and first-degree relatives. Compr Psychiatry 2007;48:27-33. 
24. Todarello O, Porcelli P, Grilletti F, Bellomo A. Is alexithymia related to negative symptoms of schizophrenia? A preliminary longitudinal study. Psychopathology 2005;38:310-314.

25. Stanghellini G, Ricca V. Alexithymia and schizophrenias. Psychopathology 1995;28:263-272.

26. Cedro A, Kokoszka A, Popiel A, Narkiewicz-Jodko W. Alexithymia in schizophrenia: an exploratory study. Psychol Rep 2001;89:95-98.

27. Bailey PE, Henry JD. Alexithymia, somatization and negative affect in a community sample. Psychiatry Res 2007;150:13-20.

28. Karvonen JT, Veijola J, Kokkonen P, Läksy K, Miettunen J, Joukamaa M. Somatization and alexithymia in young adult Finnish population. Gen Hosp Psychiatry 2005;27:244-249.

29. Taylor GJ, Parker JD, Bagby RM, Acklin MW. Alexithymia and somatic complaints in psychiatric out-patients. J Psychosom Res 1992;36:417424 .

30. Kooiman CG. The status of alexithymia as a risk factor in medically unexplained physical symptoms. Compr Psychiatry 1998;39:152-159.

31. Honkalampi K, Hintikka J, Tanskanen A, Lehtonen J, Viinamaki H. Depression is strongly associated with alexithymia in the general population. J Psychosom Res 2000;48:99-104.

32. Maaranen P, Tanskanen A, Honkalampi K, Haatainen K, Hintikka J, Viinamaki H. Factors associated with pathological dissociation in the general population. Aust N Z J Psychiatry 2005;39:387-394.

33. Sayar K, Kose S, Grabe HJ, Topbas M. Alexithymia and dissociative tendencies in an adolescent sample from Eastern Turkey. Psychiatry Clin Neurosci 2005;59:127-134.

34. Franz M, Popp K, Schaefer R, Sitte W, Schneider C, Hardt J, et al. Alexithymia in the German general population. Soc Psychiatry Psychiatr Epidemiol 2008;43:54-62.

35. Salminen JK, Saarijarvi S, Aarela E, Toikka T, Kauhanen J. Prevalence of alexithymia and its association with sociodemographic variables in the general population of Finland. J Psychosom Res 1999;46:75-82.

36. Parker JD, Taylor GJ, Bagby RM. The alexithymia construct: relationship with sociodemographic variables and intelligence. Compr Psychiatry 1989;30:434-441.

37. Todarello O, Taylor GJ, Parker JD, Fanelli M. Alexithymia in essential hypertensive and psychiatric outpatients: a comparative study. J Psychosom Res 1995;39:987-994.

38. Blanchard EB, Arena JG, Pallmeyer TP. Psychometric properties of a scale to measure alexithymia. Psychother Psychosom 1981;35:64-71.
39. Mason O, Tyson M, Jones C, Potts S. Alexithymia: its prevalence and correlates in a British undergraduate sample. Psychol Psychother 2005; 78:113-125.

40. Bankier B, Aigner M, Bach M. Alexithymia in DSM-IV disorder: comparative evaluation of somatoform disorder, panic disorder, obsessivecompulsive disorder, and depression. Psychosomatics 2001;42:235-240.

41. Subic-Wrana C, Bruder S, Thomas W, Lane RD, Kohle K. Emotional awareness deficits in inpatients of a psychosomatic ward: a comparison of two different measures of alexithymia. Psychosom Med 2005;67:483-489.

42. Bagby RM, Parker JD, Taylor GJ. The twenty-item Toronto Alexithymia Scale--I. Item selection and cross-validation of the factor structure. J Psychosom Res 1994;38:23-32.

43. Ryu SH. Quality of life of patients with depressive disorder receiving antidepressants: relationship between quality of life and alexithymia. Korean J Psychopharmacol 2009;20:316-324.

44. Taylor GJ, Bagby RM, Parker JD. Disorders of Affect Regulation: Alexithymia in Medical and Psychiatric Illness. Cambridge: UK Cambridge University Press; 1997.

45. Lee YH, Rim HD, Lee JY. Development and validation of a Korean version of the 20-item Toronto Alexithymia Scale (TAS-20K). J Korean Neuropsychiatr Assoc 1996;35:888-899.

46. Guy W. ECDEU Assessment Manual for Psychopharmacology, Revised. NIMH Publ. (DHEW Publ. No ADM 76-338); 1976.

47. Saarijarvi S, Salminen JK, Toikka TB. Alexithymia and depression: a 1 -year follow-up study in outpatients with major depression. J Psychosom Res 2001;51:729-733.

48. Leweke F, Leichsenring F, Kruse J, Hermes S. Is alexithymia associated with specific mental disorders? Psychopathology 2012;45:22-28.

49. Lumley MA, Ovies T, Stettner L, Wehmer F, Lakey B. Alexithymia, social support and health problems. J Psychosom Res 1996;41:519-530.

50. Maggini C, Raballo A, Pelizza L, Paini M, Croci R. Subjective experience of language impairment and psychopathology in schizophrenia. Psychopathology 2003;36:17-22.

51. Pasini A, Delle Chiaie RD, Seripa S, Ciani N. Alexithymia as related to sex, age, and educational level: results of the Toronto Alexithymia Scale in 417 normal subjects. Compr psychiatry 1992;33:42-46.

52. Mattila AK, Salminen JK, Nummi T, Joukamaa M. Age is strongly associated with alexithymia in the general population. J Psychosom Res 2006;61:629-635. 